\title{
Strategy for the development of agricultural enterprises
}

\author{
Ekaterina Alpatova ${ }^{1, *}$, Irina Zenkina ${ }^{2}$, Oksana Fedosova ${ }^{3}$, Olesya Lykova ${ }^{4}$, and Tatyana \\ Krivetskaya $^{5}$ \\ ${ }^{1}$ State University of Management, 99, Ryazan Ave., 109542, Moscow, Russia \\ ${ }^{2}$ Financial University under the Government of the Russian Federation, 49, Leningradsky prosp., \\ 125993, Moscow, Russia \\ ${ }^{3}$ Rostov State Economic University (RINH), 69, Bolshaya Sadovaya Street, 344002, Rostov-on-Don, \\ Russia \\ ${ }^{4}$ Don State Technical University, 1, Gagarin Sq., 344003, Rostov-on-Don, Russia \\ ${ }^{5}$ Russian University of Economics named after G. V. Plekhanov, 36, Stremyanny Lane, 117997 , \\ Moscow, Russia
}

\begin{abstract}
The article is a development of a variation of the methodology for developing a strategy for the development of an enterprise in the field of agribusiness. The strategic development line for an agribusiness enterprise is based on a detailed analysis of the external environment and a comparison of the strengths and weaknesses of the potential of the internal environment, but the emphasis in the development strategy, unified for all agribusiness enterprises in Russia, should be uniform, as the results of this work show. Many agribusiness enterprises are not able to use a development strategy, due to the fact that they have a weak internal potential that does not allow them to realize the opportunities provided to them by a favorable external environment. An agribusiness that is in a different position, in order to use all the benefits available to enterprises that use the traditional approach in forming a development strategy, must first use a comprehensive analysis. Agromarketing is singled out as the main direction aimed at strengthening and developing the internal environment of the agribusiness organization. Agromarketing, based on the principles of customer orientation, realizing all the needs and requirements of a potential consumer of agricultural products.
\end{abstract}

\section{Introduction}

The development of an enterprise in the field of agribusiness is an important task of the state scale, ensuring the safety of society in the food saturation. The relevance of this direction during the global pandemic of a new coronavirus infection has increased many times, when some deliveries of agricultural products and food products from abroad, which were previously established, became problematic. The active development of the agricultural sphere has also become relevant, due to political factors, and the introduction of mass trade sanctions on the Russian Federation, until this period, this problem was not so

* Corresponding author :katrin.alpatova@mail.ru 
acute at the state level. Due to the above-mentioned global reasons, the development of agribusiness has become one of the priorities of the Russian economy. To support this trend, special systems of state preferential lending and insurance of future agricultural crops have been developed, tax holidays have been announced for a long time, and special simplified measures have been introduced to obtain loans to small businesses in the agricultural sector.

Despite the fact that, at present, the direction of the economy related to import substitution is updated, which previously was not always economically feasible, in view of cheaper food products and agricultural products of imported production compared to agricultural products of domestic producers. But, as it turned out, in the process of obtaining the results of the study on the project «Development of small and single-industry towns of Russia» [1], many (of the surveyed - about $80 \%$ ) enterprises of the agricultural sphere are not ready to take advantage of the favorable conditions provided by the external environment, work «the old-fashioned way», do not use innovative management methods, do not use agromarketing methods, do not analyze the market and potential consumers, therefore, a priori cannot use the development strategy and actively develop.

\section{Materials, Methods and Results}

The development of an enterprise development strategy [2] in any field of activity begins with an analysis of the state of the internal environment, its weaknesses and strengths, evaluation and identification of the most problematic and most effective, which in the future may become key success factors. At the second stage, it is necessary to assess the level of influence of macro-and micro-environment factors on the company's activities, namely, to identify the factors that have a threatening impact on the organization's activities and those factors that will have a favorable impact, create additional opportunities for its development [3]. The next step will be to compare the identified weaknesses and strengths of the internal potential of the organization with the identified negative and positive factors of the external environment that affect the organization's activities. When comparing the third stage, they are most often guided by the « $0-5 »$ scale, where the extreme estimates are: $\langle 0 »-$ an estimate that means no connection between the factors, and $« 5 »-$ an estimate that means the strongest influence between the identified factors of the internal and external environment, all other estimates are considered according to the degree of proximity to the extreme border (to « 4 » or to « $4 »)$ ). Based on the results of rating, 4 key quadrants are formed. To sum up, you need to sum up all the scores in each quadrant, and then average them (divide the resulting sum of each quadrant by the number of elements in this quadrant). After obtaining the four averaged values, they must be compared, the largest number obtained, corresponding to a specific quadrant, will be the «winning» one, namely, to determine the strategic vector of the enterprise.

In the course of consulting services, the team of authors of this work carried out the analysis described earlier on 50 enterprises of the agricultural sphere (from 2018 to 2020). The difficulty was that $75-80 \%$ of the agribusiness enterprises studied «won» the quadrant «weaknesses-favorable opportunities», which indicates that the enterprise is favored by the external environment, providing favorable opportunities for development, and the company has such a weak, undeveloped internal potential [4] that it is unrealistic to realize the opportunities presented. That is, if this quadrant wins, we cannot talk about the development strategy, the leading state of this quadrant suggests that this enterprise, in order to at least stay «afloat», must strengthen its internal positions, and only after they are strengthened, can we talk about a progressive vector of development. Most often (in $75 \%$ of cases), positions on the underdevelopment of agromarketing were considered as elements that require immediate change and strengthening. Weak market research, denial of the need 
to form a portrait of a potential consumer and his preferences, play a cruel joke with such enterprises. In this regard, the activation, strengthening and, even, the emergence of agromarketing in the activities of agricultural firms will be considered as a key factor contributing to the strategic development [5] of the enterprise in agribusiness. In addition, the most threatening factor of the microenvironment is the factor of «aggressive internal competition», so the analysis of competitiveness is a mandatory type of analysis before building a strategic vector aimed at the development of an agribusiness enterprise [6]. The analysis of competitiveness, taking into account the above results, should be part of a comprehensive analysis that allows for a more detailed analysis of the activities of a particular research object.

In order to conduct a qualitative analysis of competitiveness, it is necessary to collect two sets of data for each competitor and compare them with the data of the object of research. The two data sets are:

1. Analysis of the technical and economic state.

2. Financial analysis of the company in dynamics (ideally-for three periods).

All the factors that make up these data sets are evaluated on a 10-point scale, followed by an assessment in 4 main areas: agricultural products; price of agricultural products; sales channels of agricultural products; promotion of agricultural products on the market; (Table 1) then a «competitiveness polygon» is built, which allows you to graphically identify the «bottlenecks» of the object of study, allowing you to correct the problem areas and apply proactivity [7-10].

Next, it is necessary to evaluate the indicator «market attractiveness», its assessment should be carried out on the basis of data on the dynamics of the market of agricultural products. An important role is played by taking into account external factors: public policy, risk, etc.

To evaluate the «product competitiveness» indicator, information is required related to the set and analysis of technical and economic indicators of own agricultural products and competitive agricultural products.

Thus, the definition of a strategic development line for an agribusiness enterprise is a much longer stage, due to the fact that it is difficult to build a traditional development strategy based on the convergence of the strengths of the organization and favorable opportunities from the external factors.

The comprehensive analysis, which complements the results of the SWOT-analysis of the agricultural enterprise, is based on the assessment of the indicators identified by the authors, evaluated on a scale of 1-10 using significance coefficients determined by the decision-maker.

In order to obtain the results of a comprehensive analysis of the state of an agricultural firm, it is necessary to switch to a formalized language, namely, in order to determine the value of each of the selected criteria, it is necessary to perform calculations using formula 1 , namely, to calculate the actual evaluation of the $\mathrm{i}$-th criterion for the $\mathrm{r}$-th indicator of the product $\mathrm{m}$, taking into account the weight coefficients $\left(\mathrm{D}_{\text {irm }}\right)$, will be based on the formula 1:

$$
\mathrm{D}_{\mathrm{irm}}=\mathrm{V}_{\mathrm{ir}} * \mathrm{C}_{\mathrm{irm}}
$$

$\mathrm{n}$ - the number of agricultural products produced by the agricultural enterprise;

$\mathrm{m}$ - the index of the product, and changes $\mathrm{m}=1, \mathrm{n}$;

$\mathrm{r}$ - the number of the complex indicator, $\mathrm{r}=\mathrm{I}$, II, III. (Fig. 1);

$\mathrm{I}_{\mathrm{r}}$ - the number of criteria used to calculate the $\mathrm{r}$-th indicator;

$\mathrm{i}$ - criterion number, $\mathrm{i}=1, \mathrm{I}_{\mathrm{r}}$;

$\mathrm{V}_{\mathrm{ir}}$ - weight of the $\mathrm{i}$-th criterion by the $\mathrm{r}$-th indicator, $\mathrm{V}_{\mathrm{ir}}=1-10$;

$\mathrm{C}_{\mathrm{irm}}$ - the value of the $\mathrm{i}$-th criterion for the $\mathrm{r}$-th indicator for the product $\mathrm{m}$ (point score). 
Table 1. A table for obtaining a point assessment of the competitiveness of an agricultural firmthe object of research relative to agricultural firms-competitors

\begin{tabular}{|c|c|c|c|c|}
\hline \multirow[b]{2}{*}{ Factors of firm competitiveness } & \multicolumn{4}{|c|}{ Point score } \\
\hline & $\begin{array}{l}\text { Agricultural } \\
\text { firm- } \\
\text { competitor } \\
\text { №1 } \\
\end{array}$ & $\begin{array}{l}\text { Agricultural } \\
\text { firm- } \\
\text { competitor } \\
\text { №2 }\end{array}$ & $\begin{array}{l}\text { Agricultur } \\
\text { al firm- } \\
\text { competitor } \\
\text { №3 }\end{array}$ & $\begin{array}{l}\text { Agricultur } \\
\text { al firm - } \\
\text { object of } \\
\text { research }\end{array}$ \\
\hline 1. Agricultural product & $\mathrm{a}_{11}$ & $\mathrm{a}_{21}$ & $\mathrm{a}_{31}$ & $\mathrm{a} 41$ \\
\hline Quality & $\mathrm{a}_{12}$ & a22 & a32 & a 42 \\
\hline Brand Prestige & $a_{13}$ & $a_{23}$ & $a_{33}$ & a43 \\
\hline Overall dimensions & $\mathrm{a}_{14}$ & $a_{24}$ & a34 & a44 \\
\hline Uniqueness (lack of analogues) & $\mathrm{a}_{15}$ & $\mathrm{a}_{25}$ & a35 & a45 \\
\hline Security with a quality certificate & $\mathrm{a}_{16}$ & $\mathrm{a}_{26}$ & $\mathrm{a}_{36}$ & $\mathrm{a}_{46}$ \\
\hline Total points & $\sum$ & $\sum$ & $\sum$ & $\sum$ \\
\hline Average score & $\overline{\mathrm{A}}_{1}$ & $\overline{\mathrm{A}}_{2}$ & $\overline{\mathrm{A}}_{3}$ & $\overline{\bar{A}}_{3}$ \\
\hline 2. The price of agricultural products & & & & \\
\hline Market price & $a_{11}$ & a21 & a31 & a41 \\
\hline $\begin{array}{l}\text { Percentage of discount from the market } \\
\text { price to small wholesale buyers }\end{array}$ & $a_{12}$ & $\mathrm{a}_{22}$ & $a_{32}$ & $\mathrm{a} 42$ \\
\hline Total points & $\sum$ & $\sum$ & $\sum$ & $\sum$ \\
\hline Average score & $\overline{\bar{A}}_{1}$ & $\overline{\mathrm{A}}_{2}$ & $\widehat{\bar{A}}_{3}$ & $\overline{\bar{A}}_{4}$ \\
\hline 3. $\quad$ Distribution channels for & & & & \\
\hline agricultural products & $a_{11}$ & $a_{11}$ & $\mathrm{a}_{11}$ & $a_{11}$ \\
\hline Degree of market coverage & $\mathrm{a}_{12}$ & $\mathrm{a}_{12}$ & $\mathrm{a}_{12}$ & $a_{12}$ \\
\hline Placement of storage facilities & $a_{13}$ & $a_{13}$ & $a_{13}$ & $a_{13}$ \\
\hline Inventory control system & $\mathrm{a}_{14}$ & $\mathrm{a}_{14}$ & $\mathrm{a}_{14}$ & $\mathrm{a}_{14}$ \\
\hline Transportation system & $a_{15}$ & $\mathrm{a}_{15}$ & $a_{15}$ & $a_{15}$ \\
\hline Sales forms: & & & & \\
\hline - $\quad$ direct delivery & $\mathrm{a}_{16}$ & $\mathrm{a}_{16}$ & $\mathrm{a}_{16}$ & $\mathrm{a}_{16}$ \\
\hline - $\quad$ sales representatives & $\mathrm{a}_{17}$ & a17 & a17 & a17 \\
\hline - $\quad$ wholesale intermediaries & $\mathrm{a}_{18}$ & $a_{18}$ & $\mathrm{a}_{18}$ & $\mathrm{a}_{18}$ \\
\hline Total points & $\sum$ & $\bar{\Sigma}$ & $\sum$ & $\sum$ \\
\hline Average score & $\overline{\bar{A}}_{1}$ & $\overline{\bar{A}}_{2}$ & $\overline{\mathrm{A}}_{3}$ & $\overline{\mathrm{A}}_{4}$ \\
\hline 4. Promotion of tourist products on & & & & \\
\hline the market & & & & \\
\hline Advertisement: & & & & \\
\hline - for consumers & $a_{11}$ & $\mathrm{a}_{11}$ & $\mathrm{a}_{11}$ & $\mathrm{a}_{11}$ \\
\hline - for resellers & $a_{12}$ & $a_{12}$ & $a_{12}$ & $a_{12}$ \\
\hline Individual sale: & & & & \\
\hline - incentives (additional discounts, gifts, & & & & \\
\hline etc.) for consumers & $\mathrm{a}_{13}$ & $\mathrm{a}_{13}$ & $\mathrm{a}_{13}$ & $\mathrm{a}_{13}$ \\
\hline - demo trading & $\mathrm{a}_{14}$ & $\mathrm{a}_{14}$ & a14 & $\mathrm{a}_{14}$ \\
\hline $\begin{array}{l}\text { - tasting of samples of agricultural } \\
\text { products }\end{array}$ & $\mathrm{a}_{15}$ & $\mathrm{a}_{15}$ & a 15 & $\mathrm{a}_{15}$ \\
\hline - training and training of agromarkeng & & & & \\
\hline services & $\mathrm{a}_{16}$ & $\mathrm{a}_{16}$ & $\mathrm{a}_{16}$ & $\mathrm{a}_{16}$ \\
\hline Mention of products in the media & $a_{17}$ & $a_{17}$ & $a_{17}$ & $a_{17}$ \\
\hline Total points & $\sum$ & $\sum$ & $\sum$ & $\sum$ \\
\hline Average score & $\overline{\mathrm{A}}_{1}$ & $\overline{\mathrm{A}}_{2}$ & $\overline{\mathrm{A}}_{3}$ & $\overline{\mathrm{A}}_{4}$ \\
\hline Total amount of points & $\sum \sum \mathrm{A}_{1}$ & $\sum \sum \mathrm{A}_{2}$ & $\sum \sum \mathrm{A}_{3}$ & $\sum \sum \mathrm{A}_{4}$ \\
\hline
\end{tabular}

To find the ideal (in this case, the maximum) value of each specific (i-th criterion for the $\mathrm{r}$-th indicator of the product $\mathrm{m}$ ) $\mathrm{D}_{\text {irm }}$, taking into account the weight, it is necessary to 
produce the product of the corresponding weight coefficient and the maximum score of the criterion according to the formula 2 :

$$
\mathrm{D}_{\mathrm{irm}}=10 * \mathrm{~V}_{\mathrm{ir}}
$$

Figure 1 shows an approach for conducting a comprehensive analysis of an agricultural enterprise.
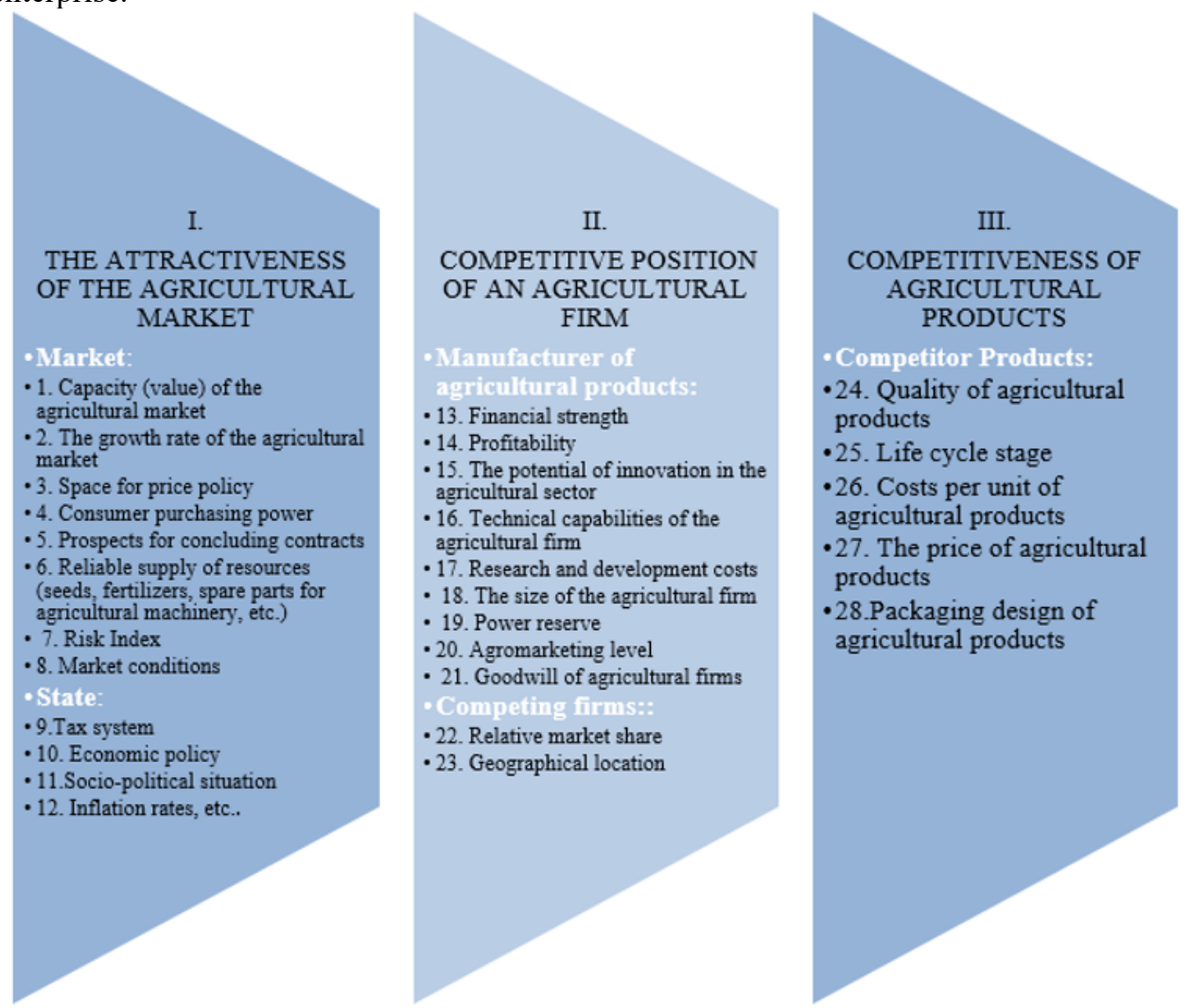

Fig. 1. A set of indicators for conducting a comprehensive analysis of an agricultural enterprise

The value of the r-th indicator for agricultural products $t$, expressed as a percentage, is calculated as the ratio of the amount of $D_{\text {ir }}$ to the amount of $D_{\text {irm }}$, then converted to a percentage state, and there will be three such calculations (based on the presence of three complex indicators). Moreover, it should be noted that if the values of the criteria are expressed in the form of natural, monetary or relative forms obtained for a group of competing firms or for products analogous to the agricultural products of the companyobject of research, then it is more convenient to calculate the estimates of the criteria without using the method of expert analysis for them [11]. Formula (3) has a universal character for each indicator, it should be used as an assessment of criteria when conducting both an analysis of the object of research with competitors, and for agricultural products. The values of the complex indicators $R_{1 t}, R_{2 t}, R_{3 t}$, obtained as a result of calculating the value of the $r$-th indicator for the agro product $t$, expressed as a percentage, fall into one of three intervals divided into three equal parts.

$$
\mathrm{Si}=\mathrm{R}_{\min }+\left[\left(\mathrm{L}_{\mathrm{i}}-\mathrm{L}_{\mathrm{imin}}\right) / \frac{\mathrm{Limax}-\mathrm{Limin}}{\mathrm{Rmax}-\mathrm{Rmin}}\right],
$$


where $S_{i}$ - the score of the i-th criterion (dimensionless value);

$\mathrm{R}_{\max }$ - the maximum number of points on the rating scale (we assume $\mathrm{Rmax}=10$ );

$\mathrm{R}_{\min }$ - the minimum number of points on the rating scale (we assume $\mathrm{Rmin}=1$ );

$\mathrm{L}_{\mathrm{i}}$ - the actual value of the $\mathrm{i}$-th criterion for the evaluated agricultural product, expressed in natural units (units, tons, rubles, etc.);

$\mathrm{L}_{\text {imax }}, \mathrm{L}_{\mathrm{imin}}$ - respectively, the lowest or highest value of the i-th criterion among competitors.

The values of complex indicators $\left(\mathrm{R}_{1 \mathrm{t}}, \mathrm{R}_{2 \mathrm{t}}, \mathrm{R}_{3 \mathrm{t}}\right)$ serve as a role for developing the actions of the agricultural firm when changing the market share and implementing a number of tactical decisions in the field of investment, program and sales policy in parallel with the status of the selected category of agricultural products.

The value of the $\mathrm{R}_{1 \mathrm{t}}$ indicator forms a strategic vector for agricultural enterprises that have agricultural products that are in high demand by consumers with a high level of quality. Such enterprises in the study sample turned out to be about $7 \%$. For such an agricultural firm, actions to maintain the strategic line will consist in the production of a greater number of different varieties of agricultural products. We predict sales growth, but, as a result, the active copying of the leading agricultural firm can predict the emergence of a large number of enterprises that can offer similar agricultural products. Demand and increasing competition will dictate the market price for agricultural products that were so popular earlier, so in such a situation, the agricultural enterprise will turn from a triumph in the market into a tough competitive price war associated with the rapid sale of agricultural products.

The value of the indicator $\mathrm{R}_{2}$ forms a strategic vector for agricultural enterprises that have agricultural products that are subject to withdrawal from the production cycle, since the volume of sales of these types of agricultural products is falling and has a negative long-term dynamics. This type of agricultural product becomes unpopular with agricultural firms, the price tends to decrease, the number of competitors will also decrease, and there is also a drop in profits, which in the near future will be characterized by the replacement of this agricultural product with a new one, more in demand by potential consumers.

The value of the $\mathrm{R}_{3 \mathrm{t}}$ indicator forms a strategic vector for agricultural enterprises that have agricultural products that require improvement or modernization. To support this strategic vector, serious investments will be required, and modernization of the formation of agricultural policy is based on mandatory specialization.

\section{Results}

Based on the results of management consulting of 50 agribusinesses, the authors of this work found that in $93 \%$ of cases, agribusinesses fell into the second and third category, therefore, the relevance of working with agro assortment and the introduction of the principles of proactive agromarketing comes out on top to solve the problems of forming and implementing the development strategy of an agricultural firm. Of the surveyed enterprises, $63 \%$ were attributed to the value of the $\mathrm{R}_{2 \mathrm{t}}$ indicator, which characterizes the assortment of agricultural products as outdated, not interesting to the potential consumer, so for such agricultural firms, it is proposed to conduct an additional ABC-analysis [12], which allows determining a more effective product policy that contributes to improving the efficiency of the enterprise in the field of agribusiness. When determining the assortment groups, it is necessary to correlate the needs of potential consumers and replace the inefficient group of agricultural products with more popular agricultural products. In $30 \%$ of cases, agribusinesses were correlated with the value of the $\mathrm{R}_{3 \mathrm{t}}$ indicator, which requires modernization and innovation, but these strategic decisions need to be actively supported financially, but often agribusinesses do not have enough own funds to invest in their own 
projects, which requires additional financial injections in the form of assistance programs and support for agriculture at the state level, as well as loans, loans, etc.

A comprehensive solution, both for the second and for the third group, was the revision of the agro assortment, taking into account the needs of the potential buyer, namely, the requirements for changing the range of agricultural products produced. The main segment of consumers is urban residents, the so-called «middle class», about $70 \%$. The analysis of agricultural products produced and sold by the group of agricultural enterprises under study revealed the following percentages of land use:

- $35 \%$ of the area is occupied by grain crops;

$-25 \%$ potatoes;

- $10 \%$ pasture feed for animal husbandry;

- $5 \%$ carrot;

- $5 \%$ beetroot;

- $5 \%$ radish;

- $3 \%$ zucchini;

- 3\% eggplant;

- $3 \%$ tomatoes;

$-2 \%$ sweet pepper;

- $1 \%$ parsley, dill, green onion, etc.

Let's start analyzing the demand for products: undoubtedly, cereals and potatoes rightfully occupy $60 \%$ of the area. Further, considering the traditional types of vegetables grown in the studied agricultural enterprises, it should be noted that the implementation (taking into account the factor of seasonality - in the summer-autumn period), the competitiveness of products does not increase.

Since the main consumers of agricultural products are residents of cities that make up the «middle class», they are forced to spend a very large amount of time in the workplace. Thus, consumers do not have (or are present in a small amount) free time for cooking. An innovative development that takes this factor into account can be the diversification of production and the creation of additional workshops for the production of frozen, sliced and prepared for the preparation of agricultural products. The release of frozen agricultural products is the sale of agricultural products all year round, (which will reduce the problem of inconsistency between the production cycle and the calendar year), and will contribute to improving the competitiveness of the agricultural firm. The demand for fruit and vegetable products is constantly present among city residents, but it is also being modernized and is subject to fashion, as it directly intersects with cooking, and, at present, a significant group of consumers have defined their lifestyle as a «healthy lifestyle» (HLS), so potential consumers have a need to eat differently from what was previously accepted in the generation of their parents or grandparents, and unconventionally, with a low calorie content, using new agricultural products (which were previously produced mainly abroad), thus, for such traditional root crops for Russian cooking as beets and black radish, the demand is actively decreasing and there is a need to replace them with more popular and popular agricultural products.

Such previously unclaimed vegetables as:

1. cauliflower are becoming very popular;

2. broccoli cabbage;

3. kohlrabi cabbage;

4. asparagus;

5. chicory;

6. artichokes, etc.

The efficiency of the use of agricultural land will increase significantly if you replace beetroot and black radish (as less popular), with more popular positions of agricultural 
products from the potential consumer. The group of solutions for maintaining active and proactive agromarketing also includes: development of branded, recognizable packaging designed for packaging vegetables; development of special «gift» options (in the form of a convenient shopping bag made of bio-raw materials with the corresponding company logo), for small-scale wholesale buyers who purchase more than $10 \mathrm{~kg}$ of vegetables at the same time. New types of vegetables (proposed to replace black radish and beets), for a wider «recognition» (and therefore the expansion of the market segment of the agricultural market), are proposed to be implemented with the addition of colorful leaflets with recipes from cauliflower, broccoli, etc. This will increase interest in new types of agricultural products and create favorable goodwill for the agricultural enterprise. The proposed methods of active agromarketing will increase profits and bring the agricultural firm to the vector of strategic development, making it more competitive and confidently developing in the world of agribusiness.

As a result of our research, we have developed a new approach to the formation of a strategy for the development of agricultural enterprises that are not quite «classically» ready to form a development strategy based on the traditional SWOT-analysis method.

\section{Conclusions}

This study was devoted to the development of an algorithm for the formation of a development strategy for an agro sphere enterprise that has an average or weak internal potential, when numerous environmental factors influence favorably. The basis for the study was the data obtained as a result of management consulting of 50 agricultural enterprises. The ratio of the studied enterprises into three groups was revealed, and the methodology is intended for two «less successful» groups of agricultural firms. The emphasis on the development of the internal potential of the agricultural enterprise was placed on the activation of the agromarketing sphere and increasing competitiveness, taking into account the needs of the main group of potential consumers of urban residents with a focus on a healthy lifestyle and with very large restrictions on the time for cooking. The developed measures in the field of proactive agromarketing will be customer-oriented and will become the main framework for strengthening the internal potential of the agricultural enterprise, which will facilitate a confident transition to the development strategy in the near future.

\section{References}

1. E. Alpatova, Yu. Markarian, Accounting and statistics, 3(51), 116-123 (2018).

2. P. Gureev, E. Dunenkova, V. Degtyareva [et al.] Business planning. (Moscow: KnoRus Publishing House Limited Liability Company) 610 (2021).

3. O. Lykova, E. Sidorenko (ISCFEC 2018) Advances in Economics, Business and Management Research 47 (Paris: Atlantis Press SARL) 580-583 (2020) https://www.atlantis-press.com/proceedings/iscfec-18/55912455

4. Tinyakova V., E. Alpatova, I. Boldyreva Innovative Technologies for Development, Justification and Adoption of Personnel Decisions (Lecture Notes in Networks and Systems) 155 1381-1388 (2021) doi 10.1007/978-3-030-59126-7_151.

5. I. Zenkina Economic Analysis: Theory and Practice, 9, 1667-1686 (2019). doi.org/10.24891/ea.18.9.1667

6. D. Morkovkin, A. Gibadullin, B. Safarov, E. Alpatova IOP Conference Series: Materials Science and Engineering, Krasnoyarsk (Krasnoyarsk: Institute of Physics and IOP Publishing Limited) 42013 (2020). doi 10.1088/1757-899X/862/4/042013. 
7. E. Alpatova Diagnostics of the economic state of the enterprise: mathematical methods and models, Saarbrücken: LAP LAMBERT Academic Publishing is a trademark of: Omni Scriptum GmbH \& Co. KG Heinrich-Böcking-Str. 6-8, 66121, Germany, 196 (2014)

8. C. Alderfer The Practice of Organizational Diagnosis: Theory and Methods (New York: Oxford University Press) (2011).

9. S. D. C. Stern, A.S. Cifu and D. Altkorn Symptom to Diagnosis: An Evidence-Based Guide (New York: McGraw-Hill) (2010).

10. J. Mcfillen, D. O’Neil, W. Balzer \& G. Varney Organizational diagnosis: an evidencebased approach. Journal of Change Management, 13, 2, 223-246 (2013) http://dx.doi.org/10.1080/14697017.2012.679290.

11. Manuel A. Fernández, Elías Bendodo, José R. Sánchez, Francisco E. Cabrera Soft Computing 23 3327-3345 (2019).

12. Mohamed Radhouane Douissa, Khaled Jabeur Soft Computing 24 9525-9556 (2020). 